OPEN ACCESS

Edited by:

Francesco Visioli,

University of Padua, Italy

Reviewed by:

Rosa Casas Rodriguez, Institut de Recerca Biomèdica August Pi i Sunyer (IDIBAPS), Spain Roberta Masella, National Institute of Health (ISS), Italy

*Correspondence: Vanessa Tita Jugha jughav@yahoo.com

Specialty section:

This article was submitted to Nutritional Epidemiology,

a section of the journal

Frontiers in Nutrition

Received: 02 November 2020 Accepted: 21 December 2020 Published: 04 February 2021

Citation:

Jugha VT, Anchang-Kimbi JK Anchang JA, Mbeng KA and Kimbi HK (2021) Dietary Diversity and

Its Contribution in the Etiology of Maternal Anemia in Conflict Hit Mount Cameroon Area: A Cross-Sectional

Study. Front. Nutr. 7:625178. doi: 10.3389/fnut.2020.625178

\section{Dietary Diversity and Its Contribution in the Etiology of Maternal Anemia in Conflict Hit Mount Cameroon Area: A Cross-Sectional Study}

\author{
Vanessa Tita Jugha ${ }^{1 *}$, Judith Kuoh Anchang-Kimbi ${ }^{1}$, Juliana Adjem Anchang ${ }^{2}$, \\ Kennedy Aminde Mbeng ${ }^{3}$ and Helen Kuokuo Kimbi ${ }^{1,4}$ \\ ${ }^{1}$ Department of Zoology and Animal Physiology, University of Buea, Buea, Cameroon, ${ }^{2}$ Pan African Institute for Development \\ - West Africa, Buea, Cameroon, ${ }^{3}$ Medico-Sanitary Engineer Sub-Divisional Hospital Mutengene, Mutengene, Cameroon, \\ ${ }^{4}$ Department of Medical Laboratory Sciences, University of Bamenda, Bamenda, Cameroon
}

Background: In the Mount Cameroon area, maternal anemia remains a major public health concern. We hypothesized that nutrient inadequacy may account for the level of anemia in pregnancy. Thus, this study examined the relative effect of dietary diversity on maternal anemia in the study area.

Methods: A total of 1,014 consenting pregnant women were enrolled in this cross-sectional study. Information on socio-demographic, antenatal characteristics, malaria and anemia control measures were documented. Dietary diversity (DD) was evaluated using the 24-h recall method and hemoglobin $(\mathrm{Hb})$ levels $(\mathrm{g} / \mathrm{dll})$ measured using a portable $\mathrm{Hb}$ meter. Malaria parasitaemia was diagnosed by blood microscopy. Anemia status was trimester specific. Logistic regression analysis was used determine predictors of maternal anemia.

Results: Among the pregnant women enrolled, the mean DD score was $3.5 \pm 0.8 \mathrm{SD}$ and only $10.4 \%$ had adequate dietary diversity. Anemia prevalence was $40.9 \%$. Majority of the women consumed starchy staples (99.3\%) while least consumed foods were dairy (4.5\%), eggs (8.3\%), fruits and vegetable (vitamin A-rich) (8.6\%). A significant lower prevalence of anemia was associated with intake of dairy $(P<0.001)$, animal protein $(P$ $=0.006)$, vitamin A-rich fruits and vegetables $(P<0.001)$. Furthermore, mean $\mathrm{Hb}$ levels were higher $(P<0.001)$ among women with diverse diets $(12.39 \pm 1.34)$ than in those with less diverse diets $(10.85 \pm 1.33)$. Predictors of anemia were as follows: study setting [Odd Ratio $(\mathrm{OR})=1.4,95 \% \mathrm{Cl}: 1.07-1.94$ ], occupation (OR $=1.9,95 \% \mathrm{Cl}: 1.16-3.43$ ), number of clinic visits $(\mathrm{OR}=1.9,95 \% \mathrm{Cl}: 1.27-2.91)$, trimester of pregnancy ( $\mathrm{OR}=3.2$, 95\% Cl: 1.45-7.38), malaria parasitaemia (OR =1.8, 95\% Cl: 1.33-2.68), out of home eating (OR $=1.4,95 \% \mathrm{Cl}: 1.03-2.13)$, and $\mathrm{DD}(\mathrm{OR}=9.8,95 \% \mathrm{Cl}: 4.56-20.80)$. The attributable risk of anemia due to dietary diversity was $82.9 \%$.

Conclusion: In the study area, DD is a major risk factor for maternal anemia. This finding underscores the importance of content specific nutrition education during clinic visits to improve intake of protein and iron-rich food in anemia prevention.

Keywords: dietary diversity, anemia, pregnant women, Mount Cameroon area, cross-sectional study 


\section{INTRODUCTION}

Pregnancy is characterized by anatomical, physiological, and biochemical changes in the woman's body. These changes are accompanied by an increase in dietary energy and nutrient requirement to support these maternal adaptations during pregnancy as well as for nutrient delivery to the fetus. Thus, for adequate nutrient uptake, a pregnant woman's diet should composed of carbohydrates, protein, vitamins, minerals, and water (1). Notwithstanding, in low- and middle-income countries (LMICs) many women living in under resourced environments, suffer from undernutrition and pregnancy presents an additional burden on the women's nutritional requirement to meet the needs of both mother and the developing fetus. Consequences of inadequate nutrient intake in pregnancy include; low birth weight, intrauterine growth restriction as well as increased risk of maternal morbidity and mortality (2). More so, inadequate consumption of energy or specific nutrients during this "critical period" may contribute to deficits in the child's development as well as compromise survival later in adult life (3).

Dietary diversity is defined as increase in the variety of foods consumed over a specific reference period (4). A diverse diet not only ensures adequate intake of essential nutrients (5), it is known to boost the immune system thereby decreasing susceptibility to malaria parasitaemia in endemic areas (6, 7). Minimum dietary diversity for women (MDD-W) is a proxy indicator of dietary nutrient adequacy. This dichotomous indicator is the consumption of five or more food out of ten food groups $(4,8,9)$. In LMICs, insufficient nutrient uptake and anemia among pregnant women are associated with monotonous starchy based diets with infrequent consumption of animal products and seasonal consumption of fruits and vegetables $(8,10)$. Foods rich in iron and vitamin $\mathrm{A}$ are known to reduce maternal anemia (11-13). Socioeconomic and cultural practices of the society in which individuals live may influence their dietary behavior (14). During antenatal care (ANC) clinics, pregnant women are educated on the health benefit of good nutrition practice in reducing anemia. Although each pregnant woman is given iron/folic acid (IFA) supplementation, they are encouraged to consume diverse food groups for adequate nutrient uptake to support pregnancy. However, this is not often the case, as financial constraints may delay early commencement of antenatal care and uptake of hematinics as well as hinder affordability of a diet rich in digestible forms of iron (15).

Globally, anemia is a major threat, affecting $\sim 38.2 \%$ of pregnant women (16) with those in LMICs accounting for $43 \%$ of the burden (17). Anemia causes are multi-factorial and contributing factors vary with geographical setting, season and dietary practice (18). A diet deficient in essential nutrients (iron, folate, vitamins A and B12) is the major cause of nutritional anemia (19) with the most prevalent being iron deficiency anemia (20). Hemoglobinopathies may increase risk of maternal anemia (21). Besides nutrient intake, other factors associated with anemia include maternal age, trimester of pregnancy (22), parity levels and ANC visit (23).
In Cameroon, antenatal care interventions such as health and nutrition-related education, screening and treatment of anemia, intermittent preventive treatment with sulphadoxinepyrimethamine (IPTp-SP), IFA supplementation and distribution of insecticide treated nets (ITNs) have been intensified to reduce anemia and malaria in pregnancy. In spite of these interventions, anemia severity (41-53.3\%) has not significantly decreased over the years in semi-urban and urbanized towns in the Mount Cameroon area (24, 25). Findings from a baseline study in the area suggest nutrient deficiency as a major contributor of anemia among pregnant women (26). Thus, we hypothesized that inadequate dietary intake may play a critical role in anemia in our setting. In this study, we described diet diversity characteristics and evaluated its contribution to anemia among pregnant women reporting for antenatal care in some medical facilities located in semi-urban and urbanized settings in the Mount Cameroon area. Findings of this study will identify contributory factors of maternal anemia and hence the designing of sustainable intervention strategies targeted at reducing anemia in pregnancy.

\section{MATERIALS AND METHODS}

\section{Study Area}

The study was carried out at ANC units in four medical facilities from two health districts: Tiko health district; Tiko Holforth health center (THHC) and Mutengene Medical Center (MMC) and Buea Health District; Buea Integrated Health Center (BIHC) and Mount Mary Hospital (MMH). These antenatal clinics were selected based on the type of locality; semi-urban (Mutengene and Tiko) and urbanized (Buea) settings.

Tiko is a semi-urban settlement located at 18 to $80 \mathrm{~m}$ above sea level (asl) between latitude $009^{\circ} 21^{\prime} 57.3^{\prime \prime} \mathrm{N}$ and longitude $04^{\circ} 04^{\prime} 22.0^{\prime \prime} \mathrm{E}$ with a population size of 147,423 inhabitants (27). The town has daily mean temperature ranging between $28^{\circ}$ and $33^{\circ} \mathrm{C}$, a relative humidity of $83.1 \%$ and an mean rainfall of $4,524 \mathrm{~mm}$ (28). This area is characterized by the presence of a local seaport that allows for fishing, import, and export of goods between neighboring countries. The rich volcanic soil encourages farming activities and industrial agriculture. This Health District hosts the Cameroon Development Corporation (CDC) plantations where banana, rubber and oil palm are cultivated and exported.

Mutengene is a road junction, semi-urban town located at 240 meters above sea level (asl) between latitude $009^{\circ} 18^{\prime} 52.8^{\prime \prime} \mathrm{N}$ and longitude $04^{\circ} 05^{\prime} 37.2^{\prime \prime} \mathrm{E}$ with 40,000 inhabitants. Farming and business constitute the mainstay of the town. The mean temperature and relative humidity are $25.08^{\circ} \mathrm{C}$ and $83 \%$, respectively [Cameroon Development Corporation (CDC) weather record].

Buea is an urbanized town located at $896 \mathrm{~m}$ asl between latitude $4^{\circ} 9^{\prime} 9.72^{\prime \prime} \mathrm{N}$ and longitude $9^{\circ} 14^{\prime} 27.6^{\prime \prime} \mathrm{E}$ with a population of 43,000 inhabitants. Buea is characterized by mean temperature range of $18-27^{\circ} \mathrm{C}$, relative humidity of $80 \%$ and rainfall of $4,000 \mathrm{~mm}$ (29). Common occupational activities in this 
area include teaching in the public and private educational institutions, civil servants, and business owners (30).

The Mount Cameroon area has two distinct seasons: a rainy season, which spans from March to October with maximum rainfall (2000-10,000 mm) in August and September. The dry season lasts for 4 months (November-February) (31). Plasmodium falciparum is the major plasmodium species in the area $(32,33)$.

THHC, MMC, BIHC and MMH offer services for antenatal care, preventive, curative, and delivery at low costs (34). In the study area, nearly all pregnant women attend ANC clinic at least once, but only $62 \%$ complete the recommended four or more ANC visits, with majority (73\%) registering for ANC initiation in the second trimester of pregnancy (25). Pregnant women living in the Mount Cameroon area are commonly exposed to $P$. falciparum infection (peripheral blood infection) with prevalence range of $13.4-22.4 \%(24,35)$. In Cameroon, the transition from a two to three doses of IPTp-SP policy took place in 2012 (36). Recent findings revealed a significant improvement in the uptake of $\geq 3$ doses of SP in this area with a coverage of $47 \%$ (25). Additional benefits of repeated doses of SP in combination with ITNs use in reducing peripheral malaria parasitaemia and maternal anemia have been reported in the area (24). Though malaria-related anemia has decreased over the years, about $75 \%$ of the anemic cases are non-malaria related (26).

\section{Sampling Design, Population, and Sampling Procedure}

A descriptive and analytical cross-sectional study comprising of pregnant women attending ANC visit in four health facilities in semi-urban and urbanized settings in the Mount Cameroon area was carried out from July, 2018 to September, 2019.

The population sample size was determined using the Cochrane formulae for cross-sectional studies (37)

$$
N=\frac{Z^{2} P(1-P)}{d^{2}}
$$

The sample size $\mathrm{N}$ was calculated based on the maternal anemia prevalence (p) of $\sim 40 \%$ (24), a margin of error of $5 \%, 95 \%$ confidence interval (CI), and an attrition rate of $10 \%$. The minimum sample size per health district was 408 . A non-probability sampling technique was used to enroll consenting pregnant women between the ages 15-49 years reporting for ANC initiation or follow-up. Recruitment involved approaching participants who were available (convenience) and after informing them of the study, those who met the eligibility criteria and gave their consent were enrolled consecutively. Pregnant women with reported history of hypertensive disorders, diabetes, or preeclampsia were excluded from the study.

\section{Questionnaire Survey}

An interview-guided structured questionnaire was used to record information pertaining to maternal socio-demographic characteristics, obstetric data, IPTp-SP, IFA uptake, ITN usage, medical history as well as dietary intake 24 -h prior to survey. Adequate IPTp-SP uptake was defined as uptake of at least 3 or more SP doses as stipulated by the World Health Organization (36). Complete ANC attendance was defined as four or more clinic visits during pregnancy (38). The questionnaire on MDD$\mathrm{W}$ guided obtention of data on dietary diversity (4).

\section{Dietary Assessment}

Minimum dietary diversity was assessed qualitatively using the $24-\mathrm{h}$ recall method. This reference period was considered appropriate because it is less prone to recall error, less cumbersome for the respondents and corresponds with the time period used in several studies on DD (39). Each study participant was asked to list and describe the exact composition of all food items and drinks consumed (day or night) prior to survey (40). Foods consumed out of the home during the specified period were assessed.

Dietary diversity scores were estimated using 10 food groups which include; (1) grains, white roots, tubers and plantains (starchy staples), (2) pulses (beans, peas and lentils), (3) nuts and seeds, (4) dairy products, (5) meat, poultry and fish, (6) eggs, (7) dark green leafy vegetables, (8) vitamin A-rich food group (fruits and vegetables), (9) vegetables and (10) fruits. Consumption of food within any food group, equivalent to one tablespoon, was assigned a score $(4,39)$. Furthermore, the total score per participant was calculated as the sum total of the scores for the different food groups consumed (41). Women who consumed $<5$ food groups were considered to have a poor DD (score range: $1-4)$ and those who consumed at least 5 food groups were considered to have a good DD (score range: 5-10) (4).

\section{Sample Collection and Laboratory Analysis}

Venous blood sample $(2 \mathrm{ml})$ was collected from each pregnant woman by a licensed laboratory technician using standard procedures. Hemoglobin $(\mathrm{Hb})$ levels were determined using a portable Urit $12^{\circledR}$ Hb meter (URIT Medical Electronics Co., Ltd. Guangxi, China) and values documented to the nearest $0.1 \mathrm{~g} / \mathrm{dl}$. Anemia status was trimester specific and defined as follows; $\mathrm{Hb}$ $<11.0 \mathrm{~g} / \mathrm{dl}$ for women in the first (1-13 weeks of gestation) and third ( $\geq 27$ weeks of gestation) trimesters and $\mathrm{Hb}<10.5 \mathrm{~g} / \mathrm{dl}$ for those in the second trimester (14-26 weeks of gestation) $(38,42,43)$. Blood films were prepared for the detection of malaria parasitaemia (44). Briefly, two drops of whole blood were placed on a labeled glass slide, thick and thin blood smears were prepared and air-dried. The thin blood films were fixed in absolute methanol for $30 \mathrm{~s}$ and later both films were stained with $10 \%$ Giemsa for $15 \mathrm{~min}$ and examined under a light microscope by two independent microscopists. A smear was declared positive for malaria parasitaemia if any asexual forms of $P$. falciparum were identified after examining 100 high power fields (44).

\section{Ethical Considerations}

The study protocol was reviewed and approved by the Institutional Review Board of the University of Buea (Ref No: 2019/967-05/UB/SG/IRB/FHS). Administrative authorization was obtained from the South West Regional Delegation of Public Health, Buea. Participation in the study was voluntary and individuals who gave their consent signed a written consent form. 


\section{Data Analysis}

Data was analyzed using IBM SPSS statistics software version 20. For continuous variables, the Kolmogorov-Smirnov test was used to check for normality and variables summarized into mean and standard deviation (SD). Proportions were used to describe categorical variables. Student $t$-test was used to compare the mean $\mathrm{Hb}$ levels per MDD-W categories. Pearson Chi-square test $\left(\chi^{2}\right)$ was used to evaluate differences in proportions.

The main outcome (dependent) variable was anemia. Covariates (independent variables) included; maternal age, setting, marital status, occupation, educational level, climatic season of enrolment, gravidity status, trimester of pregnancy, number of ANC visits, malaria parasite status, SP doses, ITN usage, out of home eating, and MDD-W. Prior to multivariable regression analysis, confounders were checked for collinearity by examining the variance inflation factor (VIF). Multicollinearity was absent with all covariates having a VIF $<2$. Binary logistic regression model (enter method) was run to examine the independent effect of covariates on anemia status. All 1,014 participants were included in the model. The attributable risk (AR\%) of anemia due to dietary diversity was calculated using an established method (45). Significant levels were set at $95 \%$ confidence interval (CI); $P<0.05$.

\section{RESULTS}

\section{Characteristics of the Study Population}

Of the 1,014 consenting pregnant women enrolled, 79 were from THHC, 430 from MMC, 163 from MMH and 342 from BIHC. In general, 50.2 and $49.8 \%$ of the participants were from Tiko health district (THD) and Buea health district (BHD), respectively. With respect to gestational age, majority of these women were in their second (41.2\%) and third (55.4\%) trimesters of pregnancy (Table 1). Mean $( \pm S D)$ maternal age was 26.7 \pm 5.48 (range;15-46 years). Trading (business) was the most common occupational activity $(43.6 \%)$, while only $14.6 \%$ were civil servants. About $42 \%$ were housewives, farmers, or students. More than half (62.2\%) of the women were married. The highest level of education attained by most $(53.1 \%)$ of the women was secondary education. Unexpectedly, majority of women attended $<4$ ANC visits (77.3\%) and only $12.2 \%$ had adequate IPTp-SP uptake ( $\geq 3$ SP doses). Maternal age, educational level, occupational status, gravidity, trimester of pregnancy, IPTp-SP uptake and ITN usage varied between the two health districts. Meanwhile, marital status, ANC attendance and malaria parasite status were comparable between health districts (Table 1).

\section{Dietary Diversity}

The mean $( \pm S D)$ MDD score of the study population was $3.57 \pm 0.82$ (score range: $1-7$ ). Of the 1,014 women, $10.4 \%$ (95\% CI: 8.6-12.4; $n=105)$ met the FAO criteria for MDD-W, whereas, 89.6\% (95\% CI: 87.7-91.4; $n=909)$ of the participants consumed diets with $<5$ food groups. Considering the different foods consumed 24-h prior to study, nearly all women (99.3\%) ate starchy staples, more than three-quarters $(86.2 \%)$ consumed animal products (meat, poultry, fish), two-third (67.5\%) of the women consumed
TABLE 1 | Baseline characteristics of the study population per study setting.

\begin{tabular}{|c|c|c|c|c|c|}
\hline Variables & Categories & THD \% (n) & BHD \% (n) & Total \% $(N)$ & $P$ value \\
\hline \multirow{3}{*}{$\begin{array}{l}\text { Age }(15-46 \\
\text { years) }\end{array}$} & $\leq 20$ & $19.6(100)$ & $8.9(45)$ & $14.3(145)$ & $<0.001$ \\
\hline & $21-25$ & $29.7(151)$ & $28.5(144)$ & 29.7 (295) & \\
\hline & $>25$ & 50.7 (258) & $62.6(316)$ & $56.6(574)$ & \\
\hline \multirow[t]{2}{*}{ Marital Status } & Single & 39.7 (202) & $35.8(181)$ & $37.8(383)$ & 0.207 \\
\hline & Married & $60.3(307)$ & $64.2(324)$ & $62.2(631)$ & \\
\hline \multirow{3}{*}{$\begin{array}{l}\text { Educational } \\
\text { level }\end{array}$} & Primary & $28.3(144)$ & $11.9(60)$ & $20.1(204)$ & $<0.001$ \\
\hline & Secondary & $58.0(295)$ & $48.1(243)$ & 53.1 (538) & \\
\hline & Tertiary & $13.8(70)$ & $40.0(202)$ & $26.8(272)$ & \\
\hline \multirow{5}{*}{$\begin{array}{l}\text { Occupation } \\
\text { status }\end{array}$} & Housewife & $18.7(95)$ & $14.3(72)$ & $16.5(167)$ & $<0.001$ \\
\hline & Farmer & $9.4(48)$ & $2.2(11)$ & $5.8(59)$ & \\
\hline & Business & $47.2(240)$ & $40.0(202)$ & $43.6(442)$ & \\
\hline & Students & $14.9(76)$ & 24.2 (122) & 19.5 (198) & \\
\hline & Civil servants & $9.8(50)$ & $19.4(98)$ & $14.6(14.8)$ & \\
\hline \multirow[t]{2}{*}{ No of ANC } & $<4$ clinic visits & 77.6 (395) & 77.0 (389) & $77.3(784)$ & 0.827 \\
\hline & $\geq 4$ clinic visits & $22.4(114)$ & $23.0(116)$ & 22.7 (230) & \\
\hline \multirow[t]{3}{*}{ Gravidity } & Primigravid & 31.2 (159) & 38.0 (192) & 34.6 (351) & 0.047 \\
\hline & Secundigravid & 25.3 (129) & $25.1(127)$ & $25.2(256)$ & \\
\hline & Multigravid & $43.4(221)$ & 36.8 (186) & $40.1(407)$ & \\
\hline \multirow{3}{*}{$\begin{array}{l}\text { Trimester of } \\
\text { pregnancy }\end{array}$} & First trimester & $2.0(10)$ & $5.0(25)$ & $3.5(35)$ & 0.033 \\
\hline & Second trimester & $41.7(212)$ & 40.8 (206) & $41.2(418)$ & \\
\hline & Third trimester & $56.4(287)$ & $54.3(274)$ & $55.3(561)$ & \\
\hline \multirow{3}{*}{$\begin{array}{l}\text { IPTp-SP dose } \\
\text { uptake }\end{array}$} & 1 dose & 64.6 (329) & $70.7(3$ & $67.7(686)$ & 0.003 \\
\hline & 2 doses & $19.6(100)$ & $20.6(104)$ & $20.1(204)$ & \\
\hline & $\geq 3 \mathrm{do}$ & $15.7(80)$ & $7(44)$ & $12.2(124)$ & \\
\hline \multirow{2}{*}{$\begin{array}{l}\text { Women who } \\
\text { own ITN }\end{array}$} & No & 28.7 (146) & $28.9(146)$ & $28.8(292)$ & 0.936 \\
\hline & Yes & $71.3(363)$ & 71.1 (359) & 71.2 (722) & \\
\hline \multirow[t]{2}{*}{ ITN usage } & No & $53.2(271)$ & $68.7(347)$ & $60.9(618)$ & $<0.001$ \\
\hline & Yes & 46.8 (238) & $31.3(158)$ & 39.1 (396) & \\
\hline \multirow[t]{2}{*}{ IFA uptake } & No & 29.5 (150) & 27.5 (139) & 28.5 (289) & 0.493 \\
\hline & Yes & 70.5 (359) & 72.5 (366) & 71.5 (725) & \\
\hline \multirow[t]{2}{*}{ Malaria status } & Negative & $81.9(417)$ & $82.6(417)$ & $82.2(834)$ & 0.787 \\
\hline & Positive & $18.1(92)$ & $17.4(88)$ & $17.8(180)$ & \\
\hline \multirow[t]{2}{*}{ MDD-W } & $<5$ food groups & $91.0(463)$ & $88.3(446)$ & 89.6 (909) & 0.167 \\
\hline & $\geq 5$ food groups & $9.0(46)$ & $11.7(59)$ & $10.4(105)$ & \\
\hline
\end{tabular}

ANC, antenatal clinic; IPTp-SP, intermittent preventive treatment in pregnancy with sulfadoxine-pyrimethamine; ITN, insecticide treated net; IFA, iron folic acid; MDD-W, minimum dietary diversity for women of reproductive age.

other vegetables. Green leafy vegetables, fruits, pulses, nuts and seeds were consumed by $29.5,21.4,17.9$, and $13.7 \%$ of the participants, respectively. Intake of dairy products (4.5\%), eggs (8.3\%), and vitamin A-rich fruits and vegetables (8.6\%) was minimal (Table 2).

\section{Prevalence of Maternal Anemia}

Mean $\mathrm{Hb}$ concentration among the women in the first, second and third trimester was $11.43 \pm 1.50 \mathrm{~g} / \mathrm{dl}, 10.95 \pm 1.50 \mathrm{~g} / \mathrm{dl}$, and $11.03 \pm 1.33 \mathrm{~g} / \mathrm{dl}$, respectively. The overall prevalence of anemia was $40.9 \%$ (95\% CI: 37.9-44.0; $n=415)$ (Figure 1). 


\section{Association Between Dietary Diversity, Maternal Anemia Status, and Hemoglobin Levels}

The distribution of respondents according to the different food groups in relation to their anemic status are presented in Figure 2. Intake of dairy products $(P<0.001)$, meat, fish and poultry $(P=0.006)$, eggs $(P=0.004)$, dark green leafy

TABLE 2 | Proportion of the different food groups consumed by the study participants 24-h prior to survey.

\begin{tabular}{lcc}
\hline Food groups & Frequency $(\boldsymbol{n})$ & Percentage (\%) \\
\hline Grains, white roots, tubers and plantains & 1007 & 99.3 \\
Pulses (beans, peas and lentils) & 181 & 17.9 \\
Nuts and seeds & 139 & 13.7 \\
Meat, poultry and fish (iron rich foods) & 874 & 86.2 \\
Dairy products & 46 & 4.5 \\
Eggs & 84 & 8.3 \\
Dark green leafy vegetables & 299 & 29.5 \\
Other vitamin A-rich fruits and vegetables & 87 & 8.6 \\
Other vegetables & 684 & 67.5 \\
Other fruits & 217 & 21.4
\end{tabular}

vegetables $(P=0.022)$, vitamin A-rich fruits and vegetables $(P<0.001)$, consumption of vegetables $(P<0.001)$, fruits $(P$ $<0.001)$ was significantly associated with lower prevalence of anemia (Figure 2).

Overall, the mean $\mathrm{Hb}$ levels were higher $(P<0.001)$ among women with good DD $(12.39 \pm 1.34)$ when compared with those with poor DD $(10.85 \pm 1.33)$. This observation was similar across the different trimesters of pregnancy except for the first trimester of pregnancy (Figure 3).

\section{Factors Associated With Maternal Anemia}

Binary logistic regression was performed to ascertain the determinants associated with the risk of maternal anemia. The predictor variables of anemic status were; study setting, level of education, occupation status, number of ANC clinic visits, trimester of pregnancy, malaria parasitaemia, MDD-W, and out of home eating (Table 3). Considering the odd ratios, BHD (OR $=1.4,95 \%$ CI: 1.07-1.94), secondary level of education (OR $=1.5,95 \% \mathrm{CI}: 1.07-2.31)$, civil service status $(\mathrm{OR}=1.9,95 \%$ CI: 1.16-3.43), <4 ANC visits (OR $=1.9,95 \% \mathrm{CI}: 1.27-2.91)$, third trimester of pregnancy $(\mathrm{OR}=3.2,95 \% \mathrm{CI}: 1.45-7.38)$, malaria parasitaemia $(\mathrm{OR}=1.8,95 \% \mathrm{CI}: 1.33-2.68)$, poor $\mathrm{DD}$ $(\mathrm{OR}=9.8,95 \% \mathrm{CI}: 4.65-20.80)$, and out of home eating $(\mathrm{OR}=$ 1.4, 95\% CI: 1.03-2.13) were associated with increased odds of

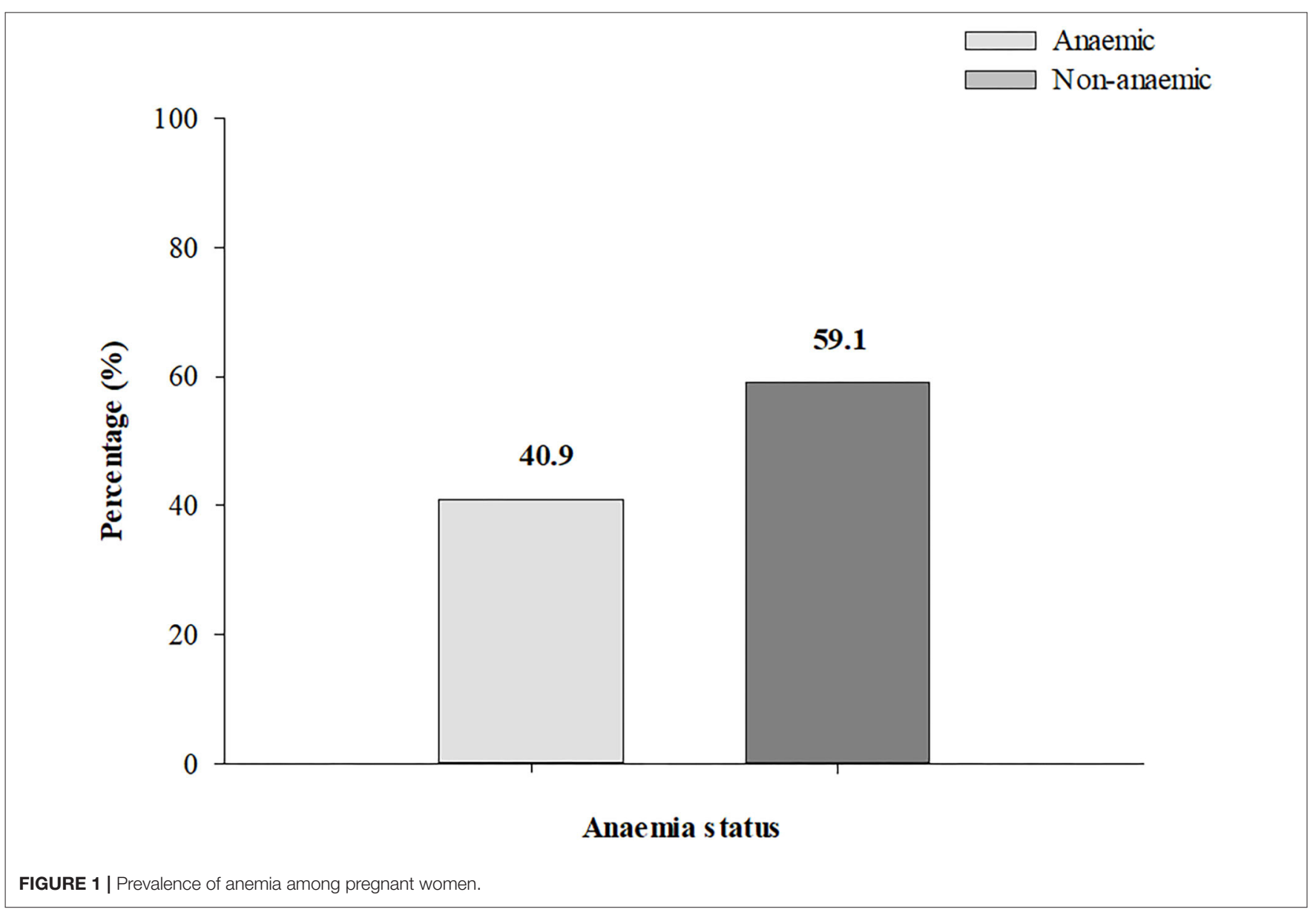




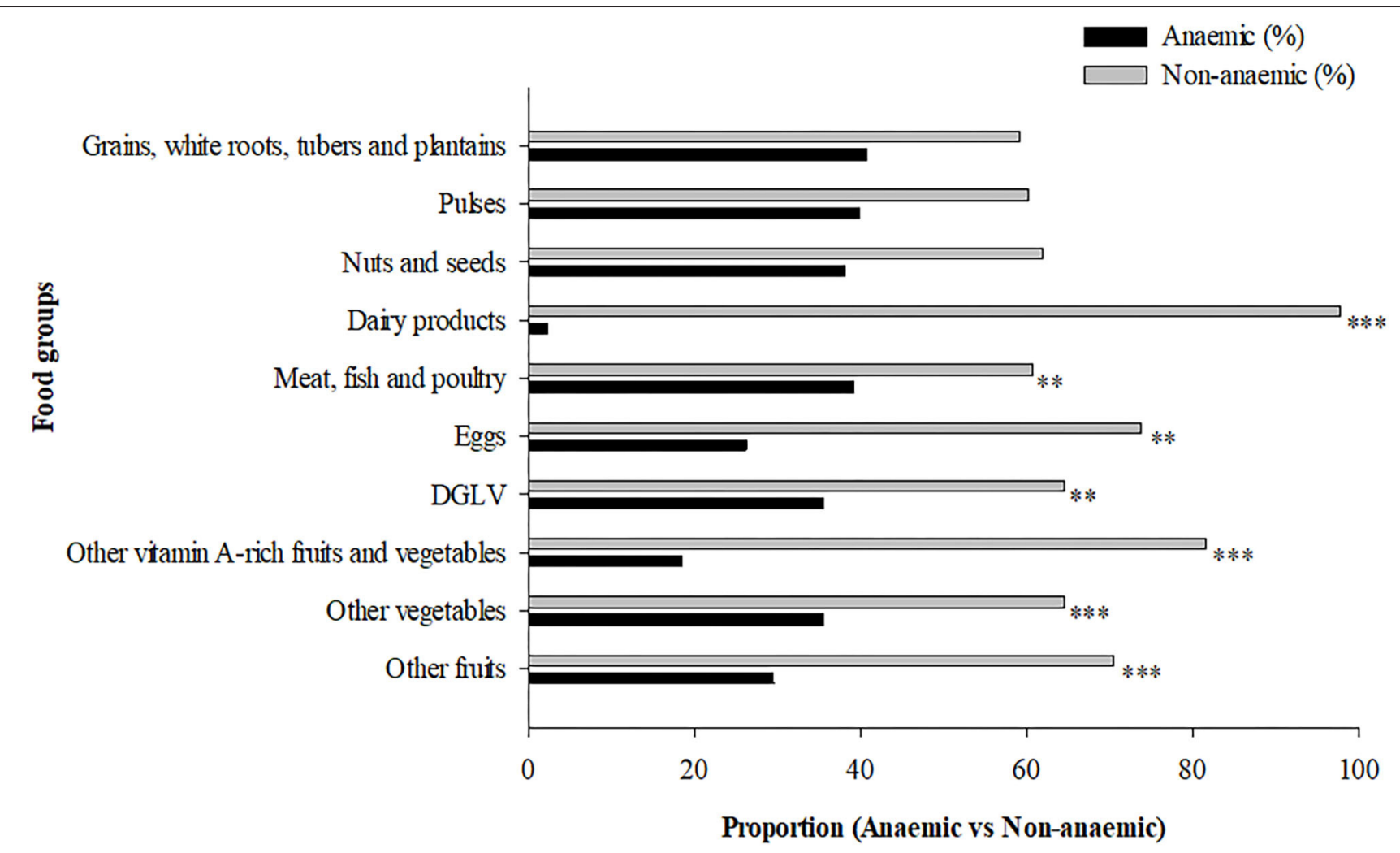

FIGURE 2 | Maternal dietary diversity during pregnancy and anemia status. ${ }^{\star \star} P<0.01,{ }^{\star \star \star} P<0.001$, Pearson Chi-square test. DGLV, dark green leafy vegetable.

anemia compared with their respective counterparts (Table 3). In addition, the attributable risk (AR\%) of maternal anemia due to dietary diversity was $82.9 \%$ (95\% CI: 60.8-105.2).

\section{DISCUSSION}

The causes of anemia are multi-factorial and the contribution of each of the factors may vary with dietary practice, geographical setting, sociodemographic, and season. This study determined the dietary diversity status of pregnant women and assessed its attribution in maternal anemia in the Mount Cameroon area. Extensive studies on DD has been conducted in several African settings, however, this is the first report on DD and its association with anemia in pregnant Cameroonian women.

The mean DD score of the pregnant women in this study was $3.5 \pm 0.8 \mathrm{SD}$ and only $10.4 \%$ of the pregnant women had adequate dietary diversity. Most (89.6\%) of the pregnant women were not consuming adequate food (below the MDD-W score recommended for pregnant women) (4). A similar finding has been reported from Oromia region, Central Ethiopia (46). Contrarily, the mean DDS in this study is less than values reported by Yeneabat et al. (47) in Northwest Ethiopia and Ayensu et al. (48) in rural and urban areas of Ghana. These variations may be attributed to socio-demographic, socio-economic, geographical, and seasonal differences (46). Higher dietary diversity or variety of foods ensures adequate intake of essential nutrients that improves the probability of good health (49). In contrast with the present study, the pregnant women consumed less than the expected classes of food, which may be linked to micronutrient deficiencies.

In this study, the diet of pregnant women in the previous $24 \mathrm{~h}$ was composed mainly of starchy food group (grains, white roots, tubers and plantains) $(99.3 \%)$, meat, poultry and fish group $(86.2 \%)$, and vegetables (67.5\%). Conversely, dairy products, eggs, fruits, and vegetables (vitamin A-rich) were least consumed foods. Comparable findings have been reported by authors in Tanzania (50), Ethiopia (46), and Kenya (51). The low socioeconomic status of women resident in the study area may be associated with the inability to afford animal products. Moreover, many women in this study setting, on average, rely on a monthly income of $<30.000$ FCFA (franc des Communautés Financières d'Afrique) ( $\sim 60$ USD) (35). Also, pregnant women may have missed scheduled ANC opportunities to be sensitized or educated on healthy lifestyle and fight against malnutrition (52). It worth noting that, more than $75 \%$ of the pregnant women attended $<4$ ANC visits. In Cameroon, averagely $65 \%$ of women in each time period receives antenatal care four or more times from any health provider (53). Since 2017, the Anglophone crisis in the Englishspeaking regions of Cameroon has affected particularly rural and peri-urban communities. These areas have been hit hardest by violence and its indigenes have become internally displaced and also making it difficult for pregnant women to attend ANC clinic in some of these areas. 

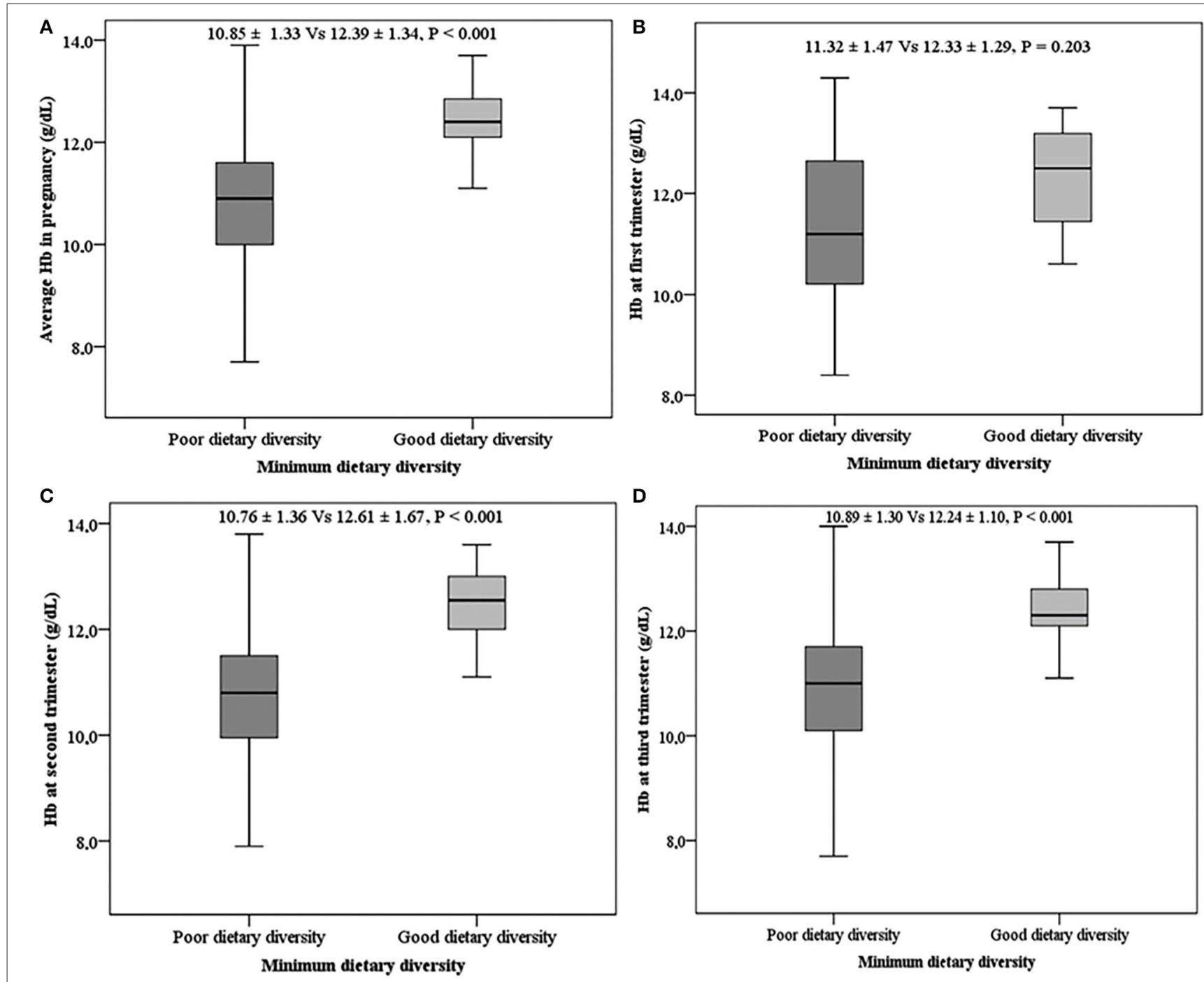

D

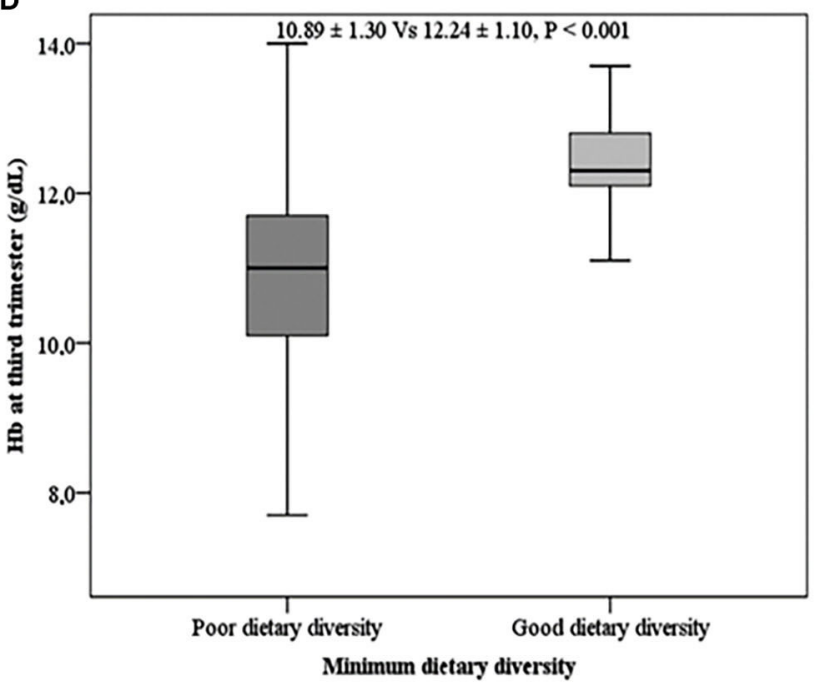

FIGURE 3 | Mean hemoglobin levels with respect to dietary diversity. (A) Mean $\mathrm{Hb}$ during pregnancy, (B) mean $\mathrm{Hb}$ in the first trimester, (C) mean $\mathrm{Hb}$ in the second trimester, (D) mean $\mathrm{Hb}$ in the third trimester.

Our findings confirm that anemia is a severe public health problem (40.9\%) in this region of the country (16). The level of anemia revealed by this study is comparable with the national prevalence (39.7\%) (range: 23.7-53.9) (53) but higher than the global average of $38.2 \%$ (16). On the other hand, the finding of this study is below the prevalence of anemia $(52.5 \%)$ in the Northern region of Cameroon (54) and in Ghana (56.5\%) (48). This demonstrates variation in the prevalence of anemia within different settings in the same country. This may be attributed specifically to geographical variations, differences in socio-economic status, cultural and dietary patterns (55).

The results of this study showed that study setting, maternal educational level, occupation status, number of ANC visits, gestational age, malaria parasitaemia, DD, and out of home eating were predictors of maternal anemia. These identified factors are discussed as follows.
Although DD is not the only contributing factor of anemia in pregnancy, the present study revealed that DD is the most pressing constraint. Low DD score ( $<5$ food groups) increased the odds of anemia by $\sim 10$ folds when compared with high DD score ( $\geq 5$ food groups). In addition, DD had a positive effect on $\mathrm{Hb}$ levels regardless of the gestational age. More so, more than $80 \%$ of anemia was attributable to dietary diversity. These findings corroborate studies by Lebso et al. (13) and Delil et al. (56) in Southern Ethiopia. However, in Northern Ghana, diet was not one of the protective factors against anemia (57). Suboptimal dietary intake increases the risk of anemia which has negative effects on the growth and development of the fetus $(21,58)$ and lactation (57). A diverse diet composed of different food groups rich in micronutrients particularly, iron, vitamin $A$, vitamin $B_{12}$, and folic acid functions to promote red blood cell production thus preventing anemia among women of reproductive age (59, 
TABLE 3 | Factors associated with maternal anemia.

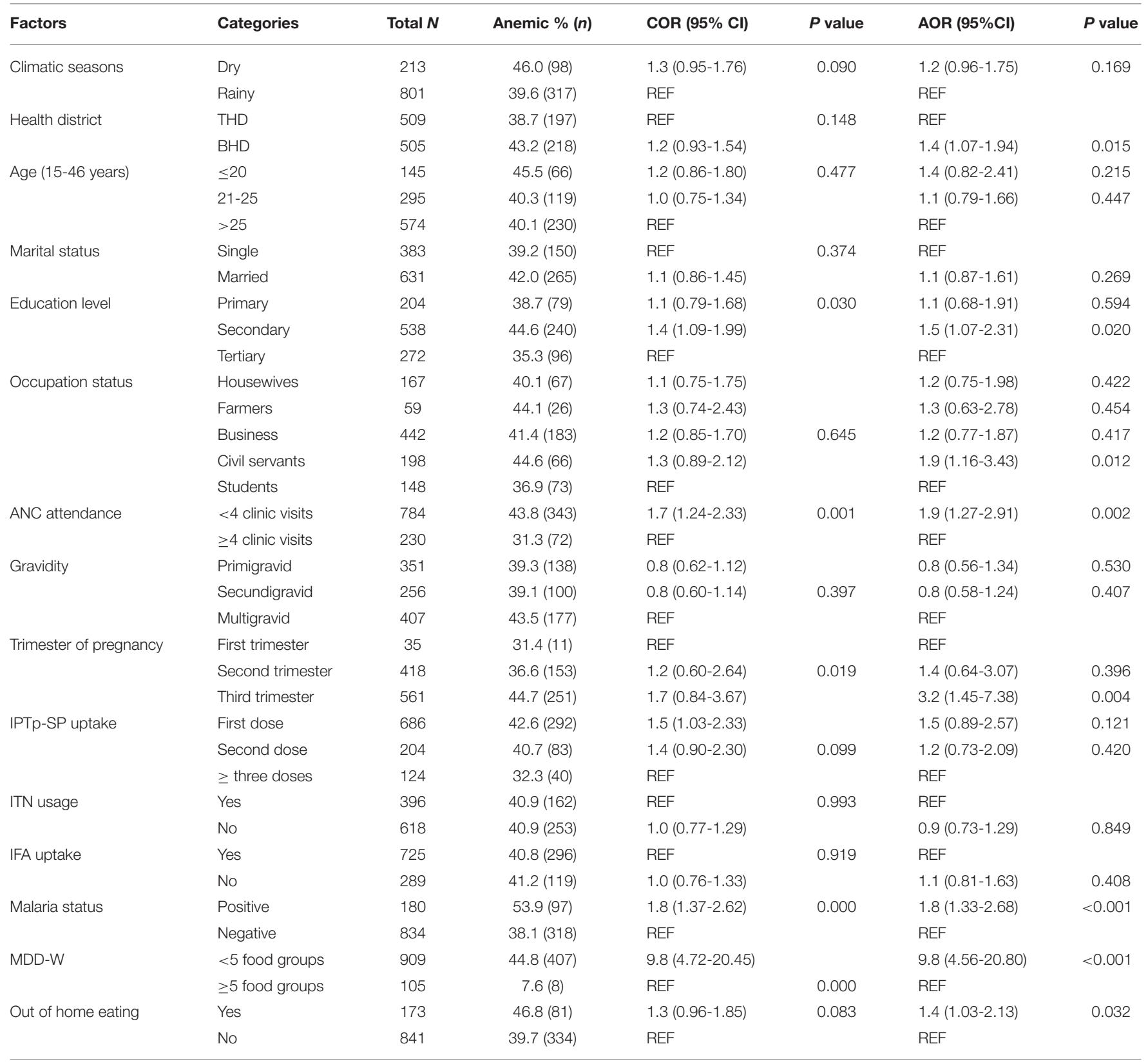

ANC, antenatal clinic; IPTP-SP, intermittent preventive treatment in pregnancy with sulfadoxine-pyrimethamine; ITN, insecticide treated net; IFA, iron folic acid uptake; MDD-W, minimum dietary diversity for women; COR crude odd ratio; AOR adjusted odd ratio.

60). This study demonstrated that women who ate out of their homes were 1.4 times more likely to be anemic. Eating out of home is associated with poor dietary quality and a predisposing factor for higher energy and fats relative to lower micronutrient intake (61). In addition, out of home foods are limited in essential nutrients especially, vitamin C, calcium, and iron $(57,62,63)$.

It is well established that malaria parasitaemia causes and/or aggravates anemia $(31,64,65)$. The occurrence of malarial anemia (23.4\%) among pregnant women is not an uncommon finding in the Mount Cameroon Area (26, 31). Although,
P. falciparum infection plays a role in the pathophysiology of anemia, however, it is not the major contributing factor of anemia in our endemic setting.

Our results showed that women who attended ANC clinic less than four times were more likely $(\mathrm{OR}=1.9)$ to be anemic. Regular ANC visits permits increase uptake of prophylactic measures against malarial infection, iron and folic acid supplementation as well as enables the pregnant woman acquire knowledge on adequate nutrition and health education (57). The number of ANC visits was seen as a strong predictor 
of anemia among pregnant women in Ghana $(57,66)$. Pregnant women in their third trimester of gestation were 3.2 times more likely to be anemic than those in their first and second trimester. The association between gestational age and anemia agrees with findings by El Aishiry et al. (67) in Egypt, Lebso et al. (13) in Ethiopia and Wemakor (68) in Ghana. During the third trimester of gestation, the haemo-dilutional effect of pregnancy and increase in nutritional demand for the mother and growing fetus are maximal (69).

Socio-demographic factors associated with the occurrence of anemia included educational status, occupation and residence. Women engaged in civil service were 1.9 times at increased risk of anemia when compared with other occupations. This could be related to missed meals, since they are busy throughout the day. Similarly, severe anemia was significantly more prevalent among women in waged labor in rural Nepali (70). Several studies have reported reduced risk of anemia in association with higher level of education $(56,71-73)$. On the contrary, this study demonstrated otherwise. This could be explained partly by bias as more than $50 \%$ of pregnant women in the study population have attained a secondary level of education. Education enable women to adopt better health seeking behaviors as well as utilization of information that are important to nutritional status. Residents in BHD were 1.4 times more affected by anemia than those of THD. This difference may be related to variation in dietary micronutrient profile and socio-demographics of these women. THD is characterized by mainly farming activities, industrial agriculture and business whereas common occupational activities in BHD include teaching in the public and private educational institutions and civil servants and business. Less anemia among residents in THD than in BHD is likely linked to availability and consumption of variety of farm produce (rich in iron) in THD. Nevertheless, further studies on dietary iron intake, iron bioavailability and maternal anemia are crucial.

\section{STRENGTHS AND LIMITATIONS}

This study confirms that anemia is an important public health problem among pregnant women in Africa and highlights the importance of simple preventive actions to increase dietary diversity by promoting nutritional education and the awareness about the importance of having a balanced diet for pregnant women. However, this study had some limitations. Only qualitative dietary assessment was done. Though quantitative methods are best for assessing nutrient adequacy, these methods are cumbersome and not affordable in limited resource settings like ours. Simple measures of dietary diversity such as MDD$\mathrm{W}$ indicator, equally, has been shown to reflect micronutrient adequacy (4). We attest that temporality is the primary limitation of cross-sectional study design. However, we used

\section{REFERENCES}

1. El-Farrash RA, Ismail EAR, Nada AS. Cord blood iron profile and breast milk micronutrients in maternal iron deficiency anemia. Pediatr Blood Cancer. (2012) 58:233-8. doi: 10.1002/pbc.23184 both descriptive and analytical cross-sectional study designs, and sufficiently large sample size population.

\section{CONCLUSION}

In general, $40.9 \%$ of the pregnant women had anemia. Only $10.4 \%$ had adequate dietary diversity while $89.6 \%$ did not meet the FAO indicator of minimum dietary diversity for women. This study revealed that diets of these women are composed mainly of starchy staples, but less of dairy products, eggs, dark green leafy vegetables, fruits, and vegetables (vitamin A-rich) as well as fruits. Intake of iron-rich diets improved $\mathrm{Hb}$ levels. The predictors of anemia were: setting, educational level, occupation, number of ANC attendance, trimester of pregnancy, malaria parasitaemia, MDD-W and eating out of home. Poor DD was a key contributor of anemia $(A R \%=82.9 \%)$. Nutritional education on the importance of a balanced diverse diet should be intensified during ANC to curb the risk of anemia in pregnancy in the Mt. Cameroon area.

\section{DATA AVAILABILITY STATEMENT}

The raw data supporting the conclusions of this article will be made available by the authors, without undue reservation.

\section{ETHICS STATEMENT}

This study, involving human participants, was reviewed, and approved by Institutional Review Board of the University of Buea. Informed consent to participate in this study was provided by the participants and/or legal guardian.

\section{AUTHOR CONTRIBUTIONS}

VJ and JA-K conceived and designed the study. VJ and KM conducted the research including data collection. VJ and JA were responsible for data management and analysis. VJ interpreted the data and wrote the first draft of the manuscript. JA-K supervised and critically revised the manuscript for important and intellectual content. HK supervised and revised the manuscript for important and intellectual content. All authors read and approved the final manuscript.

\section{ACKNOWLEDGMENTS}

The authors would like to thank all the pregnant women who participated in the study. We are equally grateful to the authorities and the health workers in the various health facilities where this study was carried out for their support and cooperation.

2. Gernand AD, Schulze KJ, Stewart CP, West Jr KP, Christian P. Micronutrient deficiencies in pregnancy worldwide: health effects and prevention. Nat Rev Endocrinol. (2016) 12:274. doi: 10.1038/nrendo.2016.37

3. Victora CG, Adair L, Fall C, Hallal PC, Martorell R, Richter L, et al. Maternal and child undernutrition: consequences for adult health and 
human capital. Lancet. (2008) 371:340-57. doi: 10.1016/S0140-6736(07)61 692-4

4. FAO F. Minimum Dietary Diversity for Women: A Guide for Measurement. Rome: FAO (2016).

5. Ahmed AU, Hill RV, Smith LC, Wiesmann DM, Frankenberger T, Gulati $\mathrm{K}$, et al. The world's most deprived: characteristics and causes of extreme poverty and hunger. Intl Food Policy Res Inst. (2007) 43:1-148. doi: 10.2499/0896297705

6. Katona P, Katona-Apte J. The interaction between nutrition and infection. Clin Infect Dis. (2008) 46:1582-8. doi: 10.1086/587658

7. Onukogu SC, Ibrahim J, Ogwuche RA, Jaiyeola TO, Adiaha MS. Role of nutrition in the management and control of malaria infection: a review. World Sci News. (2018) 107:58-71. Available online at: http://yadda.icm. edu.pl/yadda/element/bwmeta1.element.psjd-c9333114-5a34-4ecc-858061e8139e8648

8. Lee SE, Talegawkar S, Merialdi M, Caulfield LE. What Are African Women Eating During Pregnancy? Rockville, MD: Federation of American Societies for Experimental Biology (2011).

9. Kennedy G, Baye K, Powell B, Bailey A. Connecting Diverse Diets With Production Systems: Measures and Approaches for Improved Food and Nutrition Security. Encyclopedia of Food Security and Sustainability. Amsterdam: Elsevier (2018). p. 209-16. doi: 10.1016/B978-0-08-100596-5.21542-4

10. Rammohan A, Goli S, Singh D, Ganguly D, Singh U. Maternal dietary diversity and odds of low birth weight: empirical findings from India. Women Health. (2019) 59:375-90. doi: 10.1080/03630242.2018.1487903

11. Semba RD, Bloem M. The anemia of vitamin A deficiency: epidemiology and pathogenesis. Eur J Clin Nutr. (2002) 56:271-81. doi: 10.1038/sj.ejcn.1601320

12. Obwocha A, Mbagaya G, Were G. Dietary intake-among pregnant women attending ante-natal Clinic AtKisiiLevel 5 Hospital, Kenya. IOSR J Environ Sci Toxicol Food Technol. (2016) 10:77-82. doi: 10.9790/2402-1004017782

13. Lebso M, Anato A, Loha E. Prevalence of anemia and associated factors among pregnant women in Southern Ethiopia: A community based cross-sectional study. PLoS ONE. (2017) 12:e188783. doi: 10.1371/journal.pone.0188783

14. Mekonnen S, Endalamaw M. Dietary practice and associated factors among pregnant women in Gondar Town North West, Ethiopia. Int $J$ Nutrition and Food Sci. (2015) 4:707-12. doi: 10.11648/j.ijnfs.20150406.27

15. Madhavi LH, Singh HKG. Nutritional status of rural pregnant women. People's J Sci Res. (2011) 4:20-23. Available online at: https://www.pjsr.org/July11_pdf/ 5-Dr.\%20Madhavi\%20LH.pdf

16. WHO. The Global Prevalence of Anaemia in 2011. Geneva: World Health Organization (2015).

17. Rahman MM, Abe SK, Rahman MS, Kanda M, Narita S, Bilano V, et al. Maternal anemia and risk of adverse birth and health outcomes in low-and middle-income countries: systematic review and meta-analysis, 2. Am J Clin Nutr. (2016) 103:495-504. doi: 10.3945/ajcn.115.107896

18. McClure EM, Meshnick SR, Mungai P, Malhotra I, King CL, Goldenberg RL, et al. The association of parasitic infections in pregnancy and maternal and fetal anemia: a cohort study in coastal Kenya. PLoS Negl Trop Dis. (2014) 8:e2724. doi: 10.1371/journal.pntd.0002724

19. Zerfu TA, Umeta M, Baye K. Dietary diversity during pregnancy is associated with reduced risk of maternal anemia, preterm delivery, and low birth weight in a prospective cohort study in rural Ethiopia. Am J Clin Nutr. (2016) 103:1482-8. doi: 10.3945/ajcn.115.116798

20. Khalafallah AA, Dennis AE. Iron deficiency anaemia in pregnancy and postpartum: pathophysiology and effect of oral versus intravenous iron therapy. J Pregnancy. (2012) 2012:630519. doi: 10.1155/2012/630519

21. Msuya SE, Hussein TH, Uriyo J, Sam NE, Stray-Pedersen B. Anaemia among pregnant women in northern Tanzania: prevalence, risk factors and effect on perinatal outcomes. Tanzan J Health Res. (2011) 13:33-9. doi: $10.4314 /$ thrb.v13i1.60881

22. Nik Rosmawati N, Mohd Nazri S, Mohd Ismail I. The rate and risk factors for anemia among pregnant mothers in Jerteh Terengganu, Malaysia. $J$ Community Med Health Educ. (2012) 2:2161. doi: 10.4172/2161-0711.1000150

23. Mondal B, Tripathy V, Gupta R. Risk factors of anemia during pregnancy among the Garo of Meghalaya, India. J Hum Ecol. (2006) 14:27-32. Available online at: http://www.krepublishers.com/02-Journals/JHE/JHE-00-Special \%20Issues/JHE-14-Eco-Cul-Nut-Hlth-Dis-Web/JHE-SI- 14-04-027-032Mondal-B/JHE-SI-14-04-027-032-Mondal-B-Text.pdf
24. Fokam EB, Ngimuh L, Anchang-Kimbi JK, Wanji S. Assessment of the usage and effectiveness of intermittent preventive treatment and insecticidetreated nets on the indicators of malaria among pregnant women attending antenatal care in the Buea Health District, Cameroon. Malar J. (2016) 15:172. doi: 10.1186/s12936-016-1228-3

25. Anchang-Kimbi JK, Kalaji LN, Mbacham HF, Wepnje GB, Apinjoh TO, Sumbele IUN, et al. Coverage and effectiveness of intermittent preventive treatment in pregnancy with sulfadoxine-pyrimethamine (IPTp-SP) on adverse pregnancy outcomes in the Mount Cameroon area, South West Cameroon. Malar J. (2020) 19:1-12. doi: 10.1186/s12936-020-03155-2

26. Anchang-Kimbi JK, Nkweti VN, Ntonifor HN, Apinjoh TO, Chi HF, Tata $\mathrm{RB}$, et al. Profile of red blood cell morphologies and causes of anaemia among pregnant women at first clinic visit in the mount Cameroon area: a prospective cross sectional study. BMC Res Notes. (2017) 10:645. doi: 10.1186/s13104-017-2961-6

27. Tabi ESB, Eyong EM, Akum EA, Löve J, Cumber SN. Soil-transmitted Helminth infection in the Tiko Health District, South West Region of Cameroon: a post-intervention survey on prevalence and intensity of infection among primary school children. Pan Afr Med J. (2018) 30:15676. doi: 10.11604/pamj.2018.30.74.15676

28. Anguh E, Ako S, Numfor E, Josiah ZB, Ndassi V. Presence of an unmapped focus for urogenital schistosomiasis in the tiko health district in cameroon: Implications for control. Internat J Trop Disease Health. (2018) 32:1-8. doi: 10.9734/IJTDH/2018/43575

29. Nkuo-Akenji TK, Chi PC, Cho JF, Ndamukong KK, Sumbele I. Malaria and helminth co-infection in children living in a malaria endemic setting of mount Cameroon and predictors of anemia. J Parasitol. (2006) 92:1191-5. doi: 10.1645/GE-895R.1

30. Nlinwe NO. Effects of malaria on iron stores in the pregnant women of Buea and Tiko Health District, South West Region, Cameroon. J Metab Syndr. (2014) 3:4-9. doi: 10.4172/2167-0943.1000170

31. Achidi E, Kuoh A, Minang JT, Ngum B, Achimbom B, Motaze S, et al. Malaria infection in pregnancy and its effects on haemoglobin levels in women from a malaria endemic area of Fako Division, South West Province, Cameroon. J Obstet Gynaecol. (2005) 25:235-40. doi: 10.1080/01443610500 060628

32. Wanji S, Kimbi HK, Eyong JE, Tendongfor N, Ndamukong JL. Performance and usefulness of the Hexagon rapid diagnostic test in children with asymptomatic malaria living in the Mount Cameroon region. Malar J. (2008) 7:89. doi: 10.1186/1475-2875-7-89

33. Sakwe N, Bigoga J, Ngondi J, Njeambosay B, Esemu L, Kouambeng $\mathrm{C}$, et al. Relationship between malaria, anaemia, nutritional and socioeconomic status amongst under-ten children, in the North Region of Cameroon: a cross-sectional assessment. PLOS ONE. (2019) 14:e0218442. doi: 10.1371/journal.pone.0218442

34. Anchang-Kimbi JK, Achidi EA, Apinjoh TO, Mugri RN, Chi HF, Tata RB, et al. Antenatal care visit attendance, intermittent preventive treatment during pregnancy (IPTp) and malaria parasitaemia at delivery. Malar J. (2014) 13:162. doi: 10.1186/1475-2875-13-162

35. Anchang-Kimbi JK, Nkweti VN, Ntonifor HN, Apinjoh TO, Tata RB, Chi $\mathrm{HF}$, et al. Plasmodium falciparum parasitaemia and malaria among pregnant women at first clinic visit in the mount Cameroon Area. BMC Infect Dis. (2015) 15:439. doi: 10.1186/s12879-015-1211-6

36. World Health Organization. WHO Policy Brief for the Implementation of Intermittent Preventive Treatment of Malaria in Pregnancy Using SulfadoxinePyrimethamine (IPTP-SP). Geneva: World Health Organization. (2013).

37. Cochran W. Sampling Techniques. 3rd edition. New York, NY: John Wiley \& Sons Inc. (1977).

38. World Health Organization. WHO Recommendations on Antenatal Care for a Positive Pregnancy Experience. Geneva: World Health Organization (2016).

39. Lander RL, Hambidge KM, Westcott JE, Tejeda G, Diba TS, Mastiholi SC, et al. Pregnant women in four low-middle income countries have a high prevalence of inadequate dietary intakes that are improved by dietary diversity. Nutrients. (2019) 11:1560. doi: 10.3390/nu110 71560

40. Nguyen PH, Martin-Prevel Y, Moursi M, Tran LM, Menon P, Ruel MT, et al. Assessing dietary diversity in pregnant women: relative validity of the list-based and open recall methods. Curr Dev Nutr. (2020) 4:nzz134. doi: $10.1093 / \mathrm{cdn} / \mathrm{nzz1} 34$ 
41. Bukusuba J, Kikafunda JK, Whitehead RG. Food security status in households of people living with HIV/AIDS (PLWHA) in a Ugandan urban setting. $\mathrm{Br} J$ Nutr. (2007) 98:211-7. doi: 10.1017/S00071145076 91806

42. Control CfD, Prevention. Recommendations to prevent and control iron deficiency in the United States. MMWR RR. (1998) 47:1-29.

43. Hotez PJ. Empowering women and improving female reproductive health through control of neglected tropical diseases. PLoS Negl Trop Dis. (2009) 3:e559. doi: 10.1371/journal.pntd.0000559

44. Cheesbrough M. District Laboratory Practice in Tropical Countries. New York, NY: Cambridge University Press (2006). doi: 10.1017/CBO9780511543470

45. Handler A. Analytic Methods in Maternal and Child Health. Division of Science, Education, and Analysis, Health Resources and Services, Chicago, IL (1998).

46. Desta M, Akibu M, Tadese M, Tesfaye M. Dietary diversity and associated factors among pregnant women attending antenatal clinic in Shashemane, Oromia, Central Ethiopia: a cross-sectional study. J Nutr Metab. (2019) 2019:3916864. doi: 10.1155/2019/3916864

47. Yeneabat T, Adugna H, Asmamaw T, Wubetu M, Admas M, Hailu G, et al. Maternal dietary diversity and micronutrient adequacy during pregnancy and related factors in East Gojjam Zone, Northwest Ethiopia, 2016. BMC Preg Childbirth. (2019) 19:173. doi: 10.1186/s12884-019-2299-2

48. Ayensu J, Annan R, Lutterodt H, Edusei A, Peng LS. Prevalence of anaemia and low intake of dietary nutrients in pregnant women living in rural and urban areas in the Ashanti region of Ghana. PLoS ONE. (2020) 15:e0226026. doi: 10.1371 /journal.pone. 0226026

49. Hudson GJ. Food intake in a west African village. Estimation of food intake from a shared bowl. Br J Nutr. (1995) 73:551-69. doi: 10.1079/BJN199 50058

50. Ochieng J, Afari-Sefa V, Lukumay PJ, Dubois T. Determinants of dietary diversity and the potential role of men in improving household nutrition in Tanzania. PLoS ONE. (2017) 12:e189022. doi: 10.1371/journal.pone.0189022

51. Kiboi W, Kimiywe J, Chege P. Determinants of dietary diversity among pregnant women in Laikipia County, Kenya: a cross-sectional study. BMC Nutr. (2017) 3:12. doi: 10.1186/s40795-017-0126-6

52. Bhutta ZA, Darmstadt GL, Hasan BS, Haws RA. Community-based interventions for improving perinatal and neonatal health outcomes in developing countries: a review of the evidence. Pediatrics. (2005) 115(Supplement 2):519-617. doi: 10.1542/peds.2004-1441

53. World Health Organization. WHO Global Report on Traditional and Complementary Medicine 2019. Geneva: World Health Organization (2019).

54. Monteh CT, Ndié J, Sobngwi JL, Nkoum BA. Risk factors of anaemia among pregnant women in Banyo Health District, Adamawa Region of Cameroon. Central Afric J Public Health. (2019) 5:221-6. doi: 10.11648/j.cajph.20190505.17

55. Gebreweld A, Tsegaye A. Prevalence and factors associated with anemia among pregnant women attending antenatal clinic at St. Paul's hospital millennium medical college, Addis Ababa, Ethiopia. Adv Hematol. (2018) 2018:3942301. doi: 10.1155/2018/3942301

56. Delil R, Tamiru D, Zinab B. Dietary diversity and its association with anemia among pregnant women attending public health facilities in South Ethiopia. Ethiop J Health Sci. (2018) 28:5. doi: 10.4314/ejhs.v28i5.14

57. Saaka M, Oladele J, Larbi A, Hoeschle-Zeledon I. Dietary diversity is not associated with haematological status of pregnant women resident in rural areas of northern Ghana. J Nutr Metab. (2017) 2017:8497892. doi: $10.1155 / 2017 / 8497892$

58. Symington EA, Baumgartner J, Malan L, Zandberg L, Ricci C, Smuts CM. Nutrition during pregnancy and early development (NuPED) in urban South Africa: a study protocol for a prospective cohort. BMC Preg Childbirth. (2018) 18:308. doi: 10.1186/s12884-018-1943-6

59. Brooker S, Hotez PJ, Bundy DA. Hookworm-related anaemia among pregnant women: a systematic review. PLoS Negl Trop Dis. (2008) 2:e291. doi: 10.1371/journal.pntd.0000291

60. Hu S, Tan H, Peng A, Jiang H, Wu J, Guo S, et al. Disparity of anemia prevalence and associated factors among rural to urban migrant and the local children under two years old: a population based crosssectional study in Pinghu, China. BMC Public Health. (2014) 14:601. doi: 10.1186/1471-2458-14-601
61. Lachat C, Nago E, Verstraeten R, Roberfroid D, Van Camp J, Kolsteren P. Eating out of home and its association with dietary intake: a systematic review of the evidence. Obesity Rev. (2012) 13:329-46. doi: 10.1111/j.1467-789X.2011.00953.x

62. Agbozo F, Abubakari A, Der J, Jahn A. Maternal dietary intakes, red blood cell indices and risk for anemia in the first, second and third trimesters of pregnancy and at predelivery. Nutrients. (2020) 12:777. doi: 10.3390/nu12030777

63. Anwar M, Hill E, Skujins J, Huynh K, Doss C, editors. Kalico: A Smartphone Application for health-smart menu selection within a budget. In: International Conference on Smart Health. Berlin: Springer (2013). p. 113-21. doi: 10.1007/978-3-642-39844-5_14

64. Bate A, Kimbi HK, Lum E, Lehman LG, Onyoh EF, Ndip LM, et al. Malaria infection and anaemia in HIV-infected children in Mutengene, Southwest Cameroon: a cross sectional study. BMC Infect Dis. (2016) 16:523. doi: 10.1186/s12879-016-1853-z

65. Sumbele IUN, Sama SO, Kimbi HK, Taiwe GS. Malaria, moderate to severe anaemia, and malarial anaemia in children at presentation to hospital in the Mount Cameroon area: a cross-sectional study. Anemia. (2016) 2016:5725634. doi: 10.1155/2016/5725634

66. Tibambuya BA, Ganle JK, Ibrahim M. Anaemia at antenatal care initiation and associated factors among pregnant women in West Gonja District, Ghana: a cross-sectional study. Pan Afr Med J. (2019) 33:17924. doi: 10.11604/pamj.2019.33.325.17924

67. El Ashiry A, El Ghazali S, Habil I. Prevalence and determinants of anaemia in third trimester pregnancy in Fayoum governorate-Egypt. Acta Medica Mediterranea. (2014) 30:1045-51. Available online at: https:// www.actamedicamediterranea.com/archive/2014/medica-5/prevalenceand-determinants- of-anaemia-in-third-trimester-pregnancy-in-fayoumgovernorate-egypt/document

68. Wemakor A. Prevalence and determinants of anaemia in pregnant women receiving antenatal care at a tertiary referral hospital in Northern Ghana. BMC Preg Childbirth. (2019) 19:495. doi: 10.1186/s12884-0192644-5

69. Bukar M, Audu B, Sadauki H, Elnafaty A, Mairiga A. Prevalence of iron deficiency and megaloblastic anaemia at booking in a secondary health facility in north eastern Nigeria. Nigerian Med J. (2009) 50:33. Available online at: https://www.ajol.info/index.php/nmj/article/view/53263

70. Makhoul Z, Taren D, Duncan B, Pandey P, Thomson C, Winzerling J, et al. Risk factors associated with anemia, iron deficiency and iron deficiency anemia in rural Nepali pregnant women. Southeast Asian J Trop Med Public Health. (2012) 43:735. Available online at: https://www.tm.mahidol.ac.th/seameo/ 2012-43-3/23-4981-16.pdf

71. Sumbele IUN, Samje M, Nkuo-Akenji T. A longitudinal study on anaemia in children with Plasmodium falciparuminfection in the Mount Cameroon region: prevalence, risk factors and perceptions by caregivers. BMC Infect Dis. (2013) 13:123. doi: 10.1186/1471-2334-13-123

72. Melku M, Addis Z, Alem M, Enawgaw B. Prevalence and predictors of maternal anemia during pregnancy in Gondar, Northwest Ethiopia: an institutional based cross-sectional study. Anemia. (2014) 2014:108593. doi: $10.1155 / 2014 / 108593$

73. Gudeta TA, Regassa TM, Belay AS. Magnitude and factors associated with anemia among pregnant women attending antenatal care in Bench Maji, Keffa and Sheka zones of public hospitals, Southwest, Ethiopia, 2018: a cross-sectional study. PLoS ONE. (2019) 14:e0225148. doi: 10.1371/journal.pone. 0225148

Conflict of Interest: The authors declare that the research was conducted in the absence of any commercial or financial relationships that could be construed as a potential conflict of interest.

Copyright (c) 2021 Jugha, Anchang-Kimbi, Anchang, Mbeng and Kimbi. This is an open-access article distributed under the terms of the Creative Commons Attribution License (CC BY). The use, distribution or reproduction in other forums is permitted, provided the original author(s) and the copyright owner(s) are credited and that the original publication in this journal is cited, in accordance with accepted academic practice. No use, distribution or reproduction is permitted which does not comply with these terms. 